\title{
Subjectivity in Construction: Situating Desire and Pleasure in Heterosexual Relationships
}

\author{
Pankhuri Chandra ${ }^{1}$, Dr. Anuradha Sharma ${ }^{2}$
}

\section{ABSTRACT}

The present research work Subjectivity in Construction of heterosexual relationships is an attempt to understand the gender positions taken up by men and women with regard to desire and pleasure in heterosexuals. This requires an insight into the developing sexual selves of the participants. Using the qualitative technique of discourse analysis, the focus was to cultivate an image of the sexual life of these young people such that one is able to see how the elements in the construction of their sexuality have coalesced resulting in the current positions. It became evident through an analysis of the narratives, that women were very much creatures of desire and pleasure who thought about their sexual nature, their needs and fantasies. They had no qualms in admitting and accepting the same to not just themselves but also to the external world. Among the men, it was seen that men were not uni-dimensional, single-minded and self-centered with regard to sex. Intimacy and emotionality were very much part of their sexual repertoire. Thus, the focus here has not been to complete the jigsaw but to understand how these pieces have come to be a part of this puzzle, being completely aware that the results would only be an entry point to understanding how these complex structures come about.

Keywords: desire, emotionality, heterosexuals, intimacy, relationships.

We have often heard that sex is biological and gender is societal or psychical, but for me this statement does not conclude here, it sparks off a burning desire to know something more about how this phenomenon has come about. However, it is interesting to see how these two seemingly disparate notions coalesce in our minds when it comes to our understanding of sexuality. In a country like India, where sex is still a taboo and spoken about in hushed terms, even though we all have certain principles and ideals that we want to live our lives by, some of us have the strength to do so and then there are others who want to do so but cannot handle the pressure when external forces encroach upon their peace of mind and societal ideals are in conflict with individual standards. It is here that we sometimes lose the war. We allow these external forces to shape and sometimes, completely take over our psyche with regard to certain ideas.

${ }^{1} \mathrm{Ph} . \mathrm{D}$ Scholar, Amity Institute of Psychology and Allied Studies Amity University, Noida

${ }^{2}$ Amity Institute of Psychology and Allied Studies Amity University, Noida

(C) 2015 I P Chandra, A Sharma; licensee IJIP. This is an Open Access Research distributed under the terms of the Creative Commons Attribution License (http://creativecommons.org/licenses/by/2.0), which permits unrestricted use, distribution, and reproduction in any Medium, provided the original work is properly cited. 
Thus, I knew that I wanted to study sexuality and after introspecting I came to the conclusion that I wanted to study the notions of desire and pleasure within the ambit of heterosexuality. I realized that in order to do this I would need question the construction of the sexuality of young men and women in India. I wanted to know the sexual history of these individuals in order to become acquainted with the constituents that espoused their own understanding of themselves with regard to sexuality. I realized that both the male and female perspective was imperative in this study because after all femininity and masculinity are two sides of the same coin. If women take up certain subject positions in heterosexuality, it is because some other subject position has been adopted by men. Being a woman myself, the focus was on other women and how they constructed their sexuality, but then realized by focusing on women alone, we were marginalizing the experiences of men. It's true that lens was feministic; however, taking into account the history of the developing sexual character of the male gender would further enrich the research and help to understand the notion of construction with regard to gender. It would be interesting to see how men and women belonging to similar age-groups and similar social backgrounds responded to certain subjectifications and established themselves within those discourses. The research question that would be the fulcrum of this study would then be, the notions of desire and pleasure and how the participants situate themselves in their relationships with regard to these discourses of sexuality. The attempt is to understand the constructions of sexuality of young men and women where the focus would be to get to know the sexual lives of the young participants so as to gain insight into their developing sexual selves in order to see the changes that have occurred over a period of time and the possible factors that might have influenced this. The final analysis would include a collating of all the narratives based around certain themes in order to sharpen the variety of responses to them in light of the individual histories of the participants.

This research could be an entry point into whether there has been a shift in the way sex is understood in our society, if yes, then what does the future hold in terms of the way sexuality is perceived in India? And if not, then what is it that is holding us to our place in the same stagnant pool of our own characterizations? The subject matter that becomes the fulcrum of this study is the developing sexual self with regard to the notions of desire and pleasure, and the changes that have taken place over time with regard to the same underscoring the possible reasons that supplement these changes. The qualitative nature of this research would not only help us answer the research questions, but would also help us see why and how these images have taken shape in the psyche of the social order and whether or not there is evidence of a change in the cognizance that makes us who we are.

\section{REVIEW OF LITERATURE}

Wendy Hollway (1984) was a big inspiration throughout the course of this study. Her work on feminist discourses and women's heterosexual desire and gender subjectivities propelled the content of the research forward in a big way. She was criticized for this article on the premise that when an account is based on women's desires which do not simply reflect the patriarchal 


\section{Subjectivity in Construction: Situating Desire and Pleasure in Heterosexual Relationships}

contours of male dominance through heterosexuality; it contradicts an analysis which recognizes those wider inequalities. There is a proclivity to dismiss such desires because they are "ideologically constructed in discourse". Thus, it can be inferred from what Hollway's detractors have implied that there is no place for a woman's desire and pleasure in heterosexual sex. This is further reiterated in Brown's critique of Hollway's significations of openness and giving in heterosexual penetration, in saying that these notions come close to the "pseudo-reciprocal gift discourse", in which the woman gives herself to the man (her body, her virginity) and the man reciprocates by satisfying her in the form of an orgasm.

Michelle Fine's (1998) article on 'Sexuality, Schooling, and Adolescent Females: The Missing Discourse of Desire is also relevant here. She, in her exposition into the field of sex education in American public schools expounds on the discourse of desire which remains a whisper inside the official work of these schools. The naming of desire, pleasure or sexual entitlement particularly for females barely exists in the formal agenda of sex education. When talked about, it is in the context of "consequences", of emotional, physical, moral, reproductive or financial nature. The conversation represents females as the actual and potential victims of male desire. Female victimization is communicated as constructed within sexual relations with men. These views assume that if girls abstain from pre-marital sex with boys, this victimization can be avoided. A genuine discussion with regard to desire would take into account what feels good and bad, desirable and undesirable, experiences, needs, limits and responsibility. Such a discourse would free women from the position of receptivity and potential exploitation and encourage women to feel no shame or embarrassment in accepting that they are creatures of desire as well and that they have every right to assert this desire through assent and choice. In this way sex would no longer be the forbidden fruit and the young adults would be in a position to make an informed choice not just by possessing the facts about sexual inter-course but also by better understanding themselves sexually. This would also help situate adolescent females as subjects of sexuality, in the role of initiators as well as negotiator

The overriding question that arises here is that is female sexuality constructed from within masculinity and whether young women have 'a male in the head' that prevents them from fully experiencing and enjoying their sexual experiences on their own terms. A research by Tolman (2002) is relevant to this idea which examines heterosexual femininity as a project concerned with making oneself desirable rather than with feeling and expressing sexual desires. The male sex-drive discourse is inherent in these constructions as it says that men have a natural, biologically based need for sex while women are driven by a need to reproduce. Women are positioned in this construction as passive more than active subjects. Women act in response to male initiative rather than basing their actions on their own need, own desires, own choices. Though many women try to resist or negotiate with these subject positions, however, years old socializations are not easily done away with. Deviation from what considered "normal" sexual behaviour or thoughts often is accompanied by feelings of guilt, shame and confusion for women.

In a subsequent work, Tolman (2004) relays the experience of listening to boys talk about their heterosexual experiences, relational and sexual, in early adolescence, and hear the tension in 
their narratives between their longing for intimacy and attachment and the social pressure they are under to commodify sex and objectify girls in the name of establishing their masculinity ( An associated discourse is that of romance. According to Margaret Wetherill (1995), romance is also gendered. Typically, especially in the stereotypical Mills n Boon genre of romantic fiction, the women is supposed to do the romance, the man is supposed to do the sex. Anthony Giddens (1992) in his book titled, 'Transformation of intimacy', further reiterates this when he says that the rise of the notion of romantic love has given birth to the idea of a 'pure relationship'. The notion of romantic love presumes that an emotional engagement can be established, the foundation of it being inherent in the tie itself. It is this alliance, this connect between two people that cements their relationship in a way that would not be so if emotions were taken out of the equation. This concept has its own implications for both men and women. Where romantic ideals have always been a part of women's aspirations, they have an impact on men as well, albeit lesser in comparison to women. It impacts women in a way that, as Giddens puts it, it has helped put women 'in their place', which is at home, in the domestic purview but at the same time it places women as an intrinsic part of the "maleness" in the society. This means to say that where at one point in time, the notion of male-female engagement were perceived from pre-dominantly male lens but with the notion of romantic love taking precedence in context of the male-female dyad, this tendency has become somewhat altered in favor of women. In popular culture, women and girls are assigned romantic literature and men pornography, which allots them contrasting positions and identities. But these very images that these novels establish in our psyche are sometimes fraught with contradictions. For example, romantic discourses are somewhat nebulous with regard to the notion of power. On the one hand, romance seems to erase power in its image of mutuality. But more often than not, men are often represented as initiators of romance and women as receivers. Men are portrayed as heroes in the throes of romance and women are simply in the throes.

\section{METHODOLOGY}

The research method that has been used in this study is discourse analysis, specifically adhering to the Foucaultian tradition. According to Michael Arribas-Ayllon and Valerie Walkerdine (1988), a discourse can be defined as an explanation of local and heterogeneous positioning of subjects with relations of power. It not only characterizes and describes a body of knowledge but also refers to mechanisms through which certain constructs, objects and strategies come about and in this sense also posits the emergence of this knowledge with regard to the dynamics of power.

The rudiment of Foucaultian discourse analysis is the existence of the "subject" which is a position, fostered through relations of power, and how it comes into being. Foucault calls this subjectification, which refers to the construction of subjects through the technologies of power and self (Foucault 1985, 1997). This basically means that no subject position is sustained only within relations of force. A subject position is maintained through the interaction between these power relations and the technologies of self. We infer from this that a subject is constructed and maintained not only because of the existence of say a particular societal ideal, but also because 


\section{Subjectivity in Construction: Situating Desire and Pleasure in Heterosexual Relationships}

those people who are the "subjects", act in ways that purport that particular standard in order to attain an ethical goal. For example, with regard to this research, one of the subject positions could be the woman as the receptacle of the male gaze, as the passive recipient of the man's sexual desire. This subject position exists not only because the male or the society typify the woman in this manner but also because somewhere the woman behaves in a way to propagate this construction in order to be perceived as "good", "respectable" etc. It is the individual-society interaction that is the foundation of Foucaultian discourse analysis.

If we were to see this research in this light, the juxtaposition of the individual and society can be seen here in terms of the construction of sexuality and how these constructions have come into being. The subjectifications here may be that of "the good woman”, "the bad woman”, "the bold woman", "the slut", "the philandering man" etc. The reason why there could be these many and other subjectifications as well is precisely because there are two elements at play here, one of

power and one of self. If power was the only force that constituted subjects, then there would be only one subjectification.

Another recommendation for using Foucaultian discourse analysis is that according to Parker (1999), it can be carried out on autobiographical accounts. Since the nature of the research entails an in depth account of the participants' sexual history, this would provide means for being privy to continuities or discontinuities of experience over time and the way in which the participants constitute their self as an object of particular discourses. This could entail how men and women characterize and insinuate their sexuality within the discourses of desire and pleasure.

\section{Procedure}

The course of choosing participants was accomplished through the process of theoretical sampling. upper-middle class men and women, living in New Delhi, who fell between the age bracket of 18-24 were the part of this study. This was because it was important to choose participants who were more likely to talk about their sexuality, and more importantly whose sense of self was still developing with regard to their sexual experiences. This study includes both men and women in study because this would give the research more depth and an integrated perspective. The study was limited to heterosexual people because, the power dynamic that results in men and women taking up different subject positions in a relationship with one another was an important area that we wanted to explore through this study. The total number of participants in this study were five, three women (A, B and C) aged, 23, 22 and 21 and two men (D and E) aged 22 and 23 years of age, respectively. The participants were either acquaintances, people whom I didn't know very well, or people suggested by other friends and acquaintances that fit the criteria. I met each of these participants and took notes while I talked to them. I had initially planned on recording the conversations, however, none of the participants were comfortable with that. I wrote down the case histories immediately after meeting with the each participant to be sure that I wouldn't forget anything. After obtaining all my field notes, I then started to organize the narratives of the participants on the basis of the research questions that had been developed previously and began to draw parallels with the literature that I had read. 
The final picture was a collation of the individual narratives, assimilated thematically according to the research questions, while attempting to interpret, at times obvious, and other times obscure meanings behind the participant's thoughts.

\section{ANALYSIS AND DISCUSSION}

Having acquired the narratives of the participants individually, the next step was to attempt to collate the experiences of these people in such a way that that they would retain their uniqueness and at the same time could be used to find differences and similarities in their constructions. This would also help underscore the contextual aspect of these constructions thus facilitating an identification of the organization of familial structure and range of expectation and duty that sometimes become shackles that coerce us into ideology and behavior that is not inherently ours. Bringing together the narratives of the participants would also emphasize how different discourses situate themselves in the psyche of people and how these discourses are different or similar in their constructions, is something that would also come to light here. Furthermore, the subject positions that these individuals take up in heterosexuality would become evident when we examine them together in relation with each other.

When we speak of desire in the literal sense of the word, it means a need, a wish or a drive to seek out certain objects and engage in certain activities. When we speak of desire in relation to sexuality or sexual desire, we can describe it as a need, wish or drive to seek out sexual objects and engage in certain sexual activities. Thus, it can be inferred that sexual desire is subjective feeling state that can be triggered by external or internal cues and may or may not result in explicit sexual behavior. It is a state of mind in which we are subjectively "turned on" by certain stimuli and whether we act on it or not could be a function of choice, opportunity, resources etc. In the current context, we see indications of desire in the narratives of the sexual history of the participants, among both women and men. We see its articulations in A's expatiation of her first sexual experience where she says that "she felt excited", "she could not stop thinking about it". She also talks about how she and her current boyfriend with whom she is sexually active, often watch pornography to stimulate themselves. Thus they try to intensify sexual desire by watching sexually explicit stimuli and then engage in sexual activity to intensify pleasure. None of the other participants talked of sexual desire in such explicit terms, but it was nevertheless present in the backdrop of their narratives. When B says that she "had feelings for her boyfriend", and "felt good when he kissed her", and when C says that "she enjoyed kissing her boyfriend", we see desire illustrated in these verbalizations. Among the male participants as well, we see D saying that as he made his foray into puberty, the girls became something more than "the other", they became the ones who "looked pretty and smelled nice", he also said that it was at this time that he noticed the girls' bodies and how they were changing. Here we see vestiges of sexual desire and how it is starting to blossom in the young pubertal adolescent. In his noticing the bodies of his female classmates, we see the premature stirring of sexual desire. In his description of his first experience of masturbation as well, watching a sexually explicit scene from an English movie stirred his libido and got him to masturbate, something he said that happened "pretty naturally". Something similar happened with E in his first experience of masturbation as well. In 


\section{Subjectivity in Construction: Situating Desire and Pleasure in Heterosexual Relationships}

his case he had picked up the adult magazine with the specific purpose of masturbating, and even he said that it occurred very quickly and naturally without taking any effort. This is illustrative of how sexual desire, stimulated by external and internal cues manifested itself in the form of an explicit sexual activity.

Another interesting point is how there is a change in the articulation of this desire, specifically among the female participants. These women who talked about stolen glances and holding hands in their teenage, started talking about more explicit sexual activity in their current or future relationships. Even $\mathrm{C}$ who seems to have very fixed ideas about virginity and pre-marital sex talks of being more "invested" in her future relationship and says that "you can do stuff without losing your virginity”. The initial teenage hesitation among these girls could also be a function of parental pressure and expectation. The "unseen eyes" that C talks about, B's inability to look at her parents in the eye after experiencing her first kiss are possible illustrations of how it was guilt vis-à-vis their parents that became an obstacle in their experience of sexual desire. It was as if they were doing something wrong and letting their parents down and hence something that needed to be curbed. Even in the case of A, who appears to have the most libertine nature, her early experiences of sexual desire and her unapologetic enjoyment of it came from a sense of rebellion against her parents and the restrictions that they had enforced on her. In her case, parental pressure became the very catalyst that instigated her to explore it further. This phenomenon is apparent in the narratives of the male participants as well. E says that he had had crushes on some girls in his school years, however he abstained from doing anything about it, because he didn't want to get distracted. He had to live up his parents expectations because of which he kept a firm check on his desire and refrained from getting involved with any girl. D said that he could not face his parents after he first masturbated and was very jumpy for the first few days. E however, did not mention any such discomfort in his reminiscence of his first masturbatory episode, he in fact said that "there was a spring in his step the whole day". The difference between these two experiences of $\mathrm{D}$ and $\mathrm{E}$ is that $\mathrm{E}$ was studying in boarding school at that time and lived in a hostel, away from the possible condemnatory eyes of his parents where as D lived at home. Thus, D's manifestation of sexual desire was adulterated by the mere presence of his parents while E's was not, though it is evident how parental pressure and expectation were perceived as impediments to the expression of their libidinal motivation.

Pleasure can be defined as those positively valued feelings induced by sexual stimuli. This conceptualization encompasses a broad range of sexual pleasures, from the soothing sensations of sensual massage, to the explosion of feeling that accompanies orgasm. We see evidence of this notion in the narratives of the participants as well. In A saying that the boy squeezing her breast excited her, in $\mathrm{B}$ and $\mathrm{C}$ admitting that kissing their boyfriends felt good, we see the expression of this feeling of sexual pleasure. One thing that is consistent in all the narratives, of the female as well as the male participants is that all of them mentioned their preference for equality in their present of future relationships with regard to pleasure. B said that her fantasy of the perfect sexual partner would be someone who believed in equality. He would be gentle with her and yet know how to pleasure her and vice-versa. $\mathrm{C}$ opined that her fantasy of the perfect sexual partner would be somebody who would "let me take my own time", who would think 


\section{Subjectivity in Construction: Situating Desire and Pleasure in Heterosexual Relationships}

about her pleasure as well as his and be very loving with her. A said that there were times when she guided her boyfriend into doing things in a way that would intensify her pleasure and he did the same. D said that his fantasy of a perfect sexual partner would be a girl who would expressed herself and sometimes even took initiative, somebody who would sense his needs and whose needs he could sense and fulfill. Finally, E believed that he would not expect her to think of "my pleasure only". He hopes for "equal give and take between them”. Thus, it is feeling of mutuality that plays an important part in the experience of sexual pleasure among the present pool of participants. The women hoped for a partner would think about their pleasure and satisfaction as well as their own and the men envisioned a partner whose needs they could sense and thus deliver, and vice versa.

Thus, we see that none of the participants situate their subjectivities in heterosexuality with regard to Wendy Hollway's male-sexual drive discourse. We know that according to this discourse, women indulge in sexual activity for the purpose of procreation and men because of their innate, biological sexual drive but this does not seem to be the case with the present pool of participants. Since the female participants are all in the early twenties, reproduction and having children does not seem to figure in their scheme of things. They don't even speak of marriage in their narratives. They either are in relationships or have been or hope to be in one in the near future and all of them out of wedlock. They mention desire and pleasure at the level of feel and sensation not with regard to it being a means to an end. Similarly with the men, where they do address the need for their pleasure, they also mention their partner's need and satisfaction in the same breath. However, another interesting point that comes up in the narratives is that the women do not see themselves and are not seen as initiators of either the relationship or the sexual activity. They may have had feelings but they were expressed only after the guy approached them or asked them out. Even in the men's narratives, D says of his first kiss with his girlfriend, "I sensed she was ready so I took the first step and kissed her". E in relating the first time he and his girlfriend had sexual intercourse said that "it seemed that she expected me to take the lead". Thus, women and men do see women in the role of negotiators however women do not yet perceive themselves and aren't perceived by men as taking initiative in the relationship. It is possible that they do so in order to resist the subjectifications such as "forward" and "bold" which may not have a particularly positive connotation. Benjamin's (1984) notions of true and false recognition could be the reason behind this which go on to say that true recognition is only achieved when one is able to accept and embrace themselves, and all of themselves in a holistic manner, accepting the good as well as the bad parts, only then can we expect our partner to be able to do so.

The women's lack of initiative can be construed as their inability to accept that sexually agentic part of themselves, which is probably why men also do not perceive them as initiators. We see this exemplified in the popular culture of novels and movies as well. For example, in the Harlequin genre of romance novels, which is all the rage among young women, we see the man, the hero taking charge, guiding the woman in their heterosexual coupling. The woman in no way is positioned as passive, there is an elucidation of her desire and need which the hero "senses" and thus facilitating her in making a foray into the world of sexual pleasure. The "tale of change" 
that Rubin (1989) talks about in her research can be seen here as well. According to Rubin girls feel they have every right to engage in sexual activity, including sexual intercourse, at whatever age seems appropriate to them which is in consonance with the narratives of the girls in the present pool of participants. According to Rubin, changes in the sexual behaviour and attitudes of girls have been much more pronounced than among boys. In the present study as well, we can see a change in the thinking of the females from their early teenage to the present as mentioned before, but no such significant change makes itself know in the narratives of the males.

\section{CONCLUSION}

The study found that women were not entrenched within the subject positions of coy, demure, submissive and self-effacing with regard to their sexuality but were very much creatures of desire and pleasure who thought about their sexual nature, their needs, their fantasies and had no qualms in admitting and accepting them to not just themselves but also the external world. Among the men, it was seen that men were not uni-dimensional, single-minded and self-centered with regard to sex. They were not devoid of emotionality and intimacy that women are typically expected to associate with sex. Instead, they were very much slave to the affect that the act of sex subsumes in its primitive corporeality. This study could not only help us to understand the way sexuality is perceived in India today, but also underscore the direction in which we seem to be going. It would also facilitate an insight into the things holding us back and possibly enlighten the path to change that we can bring about within ourselves and ultimately in our society and can be helpful in preventing crime against women and gender biased behaviour .

\section{REFERENCES}

Fine, M. (1988). Sexuality, Schooling, and Adolescent Females: The Missing Discourse of Desire. Harvard Educational Review, 58(1), 29-54.

Giddens, A. (1992). The transformation of intimacy: Sexuality, love, and eroticism in modern societies. Stanford, Calif.: Stanford University Press.

Gill, R. (2008). Empowerment/Sexism: Figuring Female Sexual Agency in Contemporary Advertising. Feminism \& Psychology. Retrieved June 9, 2013, from http://fap.sagepub.com/

Henriques, J., \& Hollway, W. (1984). Gender Difference and the Production of Subjectivity. In Changing the subject: Psychology, social regulation and subjectivity. London: Methuen.

Kitzinger, C., \& Wilkinson, S. (1995). Feminist Discourses and Women's Heterosexual Desire. In Feminism and discourse: Psychological perspectives (pp. 86-142). London: Sage.

M, M., \& N. Davis, S. (1997). Feminist Post-Structuralist and Discourse Analysis. Towards a New Psychology of Gender, 49-63.

Tolman, D. (2002). Found(ing) Discourses of Desire: Unfettering Female Adolescent Sexuality. Dilemmas of Desire: Teenage Girls Talk about Sexuality. 